\title{
Molecular decay of enamel matrix protein genes in turtles and other edentulous amniotes
}

\author{
Robert W Meredith ${ }^{1,2}$, John Gatesy ${ }^{1}$ and Mark S Springer ${ }^{1 *}$
}

\begin{abstract}
Background: Secondary edentulism (toothlessness) has evolved on multiple occasions in amniotes including several mammalian lineages (pangolins, anteaters, baleen whales), birds, and turtles. All edentulous amniote clades have evolved from ancestors with enamel-capped teeth. Previous studies have documented the molecular decay of tooth-specific genes in edentulous mammals, all of which lost their teeth in the Cenozoic, and birds, which lost their teeth in the Cretaceous. By contrast with mammals and birds, tooth loss in turtles occurred in the Jurassic (201.6-145.5 Ma), providing an extended time window for tooth gene degradation in this clade. The release of the painted turtle and Chinese softshell turtle genomes provides an opportunity to recover the decayed remains of tooth-specific genes in Testudines.
\end{abstract}

Results: We queried available genomes of Testudines (Chrysemys picta [painted turtle], Pelodiscus sinensis [Chinese softshell turtle]), Aves (Anas platyrhynchos [duck], Gallus gallus [chicken], Meleagris gallopavo [turkey], Melopsittacus undulatus [budgerigar], Taeniopygia guttata [zebra finch]), and enamelless mammals (Orycteropus afer [aardvark], Choloepus hoffmanni [Hoffmann's two-toed sloth], Dasypus novemcinctus [nine-banded armadillo]) for remnants of three enamel matrix protein (EMP) genes with putative enamel-specific functions. Remnants of the $A M B N$ and ENAM genes were recovered in Chrysemys and retain their original synteny. Remnants of AMEL were recovered in both testudines, although there are no shared frameshifts. We also show that there are inactivated copies of AMBN, AMEL and ENAM in representatives of divergent avian lineages including Galloanserae, Passeriformes, and Psittaciformes, and that there are shared frameshift mutations in all three genes that predate the basal split in Neognathae. Among enamelless mammals, all three EMP genes exhibit inactivating mutations in Orycteropus and Choloepus.

Conclusions: Our results highlight the power of combining fossil and genomic evidence to decipher macroevolutionary transitions and characterize the functional range of different loci involved in tooth development. The fossil record and phylogenetics combine to predict the occurrence of molecular fossils of tooth-specific genes in the genomes of edentulous amniotes, and in every case these molecular fossils have been discovered. The widespread occurrence of EMP pseudogenes in turtles, birds, and edentulous/enamelless mammals also provides compelling evidence that in amniotes, the only unique, non-redundant function of these genes is in enamel formation.

Keywords: Ameloblastin, Amelogenin, Enamel matrix protein genes, Enamelin, Pseudogenes, Testudines

\footnotetext{
* Correspondence: mark.springer@ucr.edu

'Department of Biology, University of California, Riverside, CA 92521, USA

Full list of author information is available at the end of the article
} 


\section{Background}

Gnathostomes are unique among vertebrates in utilizing jaws and teeth for food acquisition and processing. Divergent gnathostome lineages exhibit a wide array of dental modifications in association with diverse dietary specializations. Multiple iterations of secondary tooth loss have also evolved in gnathostomes, perhaps most famously in birds, turtles, and several mammalian lineages including baleen whales, pangolins, and anteaters [1-3]. There are also mammalian species with enamelless teeth, i.e., sloths, armadillos, aardvarks, pygmy and dwarf sperm whales [2].

Tooth development is an intricate process that encompasses a complex series of epithelial-mesenchymal interactions involving growth factors, transcription factors, and signal receptors that affect tooth shape, tooth number, and cusp number [4-9]. Several hundred genes are associated with tooth development [6], including members of the hedgehog ( $\mathrm{Hh}$ ), fibroblast growth factor (Fgf) and bone morphogenic protein (Bmp) families that mediate epithelio-mesenchymal signaling interactions [10]. Most or all of the genes that are involved in early tooth development are thought to be pleiotropic and have additional functions outside of tooth formation. However, there are also genes with putative tooth-specific functions that are expressed later in development by dentin-forming odontoblasts and/or enamel-forming ameloblasts [11-17]. These genes affect the physical properties of teeth including enamel thickness and structure. The durability of teeth, in combination with tooth-specific genes that impact the physical structure of dentin and enamel, make teeth a model system for studying the coevolution of morphological change in the fossil record and molecular change in the genome.
Previous studies have shown that the genes encoding three enamel matrix proteins (EMPs), enamelin, amelogenin, and ameloblastin, have become pseudogenized in one or more edentulous/enamelless mammals by frameshift mutations and/or stop codons [1-3] (Table 1). Further, the molecular decay of tooth-specific genes in placental mammal lineages has been shown to parallel the morphological degeneration of enamel in the fossil record [1-3]. The retention of inactivated EMP genes in mammalian lineages is not surprising given that all edentulous and enamelless taxa appear to have originated in the Cenozoic [2].

By contrast, tooth loss in both birds and turtles occurred in the Mesozoic, providing a longer time period for the molecular decay of tooth-specific genes in these lineages. In birds, the presence of a horny beak and gizzard have presumably compensated for edentulism in food acquisition and processing [22]. Edentulism in the ancestry of modern birds occurred in the Cretaceous, between 125 and 65.5 $\mathrm{Ma}$, and also evolved independently in several lineages of extinct birds that are on the stem to Neornithes (crown group birds) [22]. Even though tooth loss in Neornithes occurred in the Cretaceous, the chicken (Gallus gallus) genome retains pseudogenized copies of both $A M E L$ and ENAM [18,20,21].

Edentulism in Testudines (turtles) occurred even earlier, at least as far back as the Late Jurassic [23,24]. The oldest turtle is Odontochelys semitestacea from the Triassic of China ( 220 Ma) [25]. Marginal and palatal teeth are both present in this taxon [25]. Slightly younger $(\sim 210 \mathrm{Ma})$ is Proganochelys quenstedti from the Upper Triassic [23,26]. Marginal teeth are absent in Proganochelys, but palatal teeth are present. Phylogenetic analyses suggest that Proganochelys, like Odontochelys, is a stem testudine [23].

Table 1 Pseudogene remnants of enamel matrix protein (EMP) genes in edentulous and enamelless amniotes

\begin{tabular}{lll}
\hline Tooth gene & Taxon & \\
\cline { 2 - 3 } & Turtles & Birds \\
\hline 1. ENAM & $\begin{array}{l}\text { Frameshift mutations in Chrysemys } \\
\text { exon 9 (Additional file 1) }\end{array}$ & $\begin{array}{l}\text { Frameshift mutations in exon } 9 \text { of Anas, Gallus, } \\
\text { Meleagris, Melopsittacus, and Taeniopygia } \\
\text { (Additional file 1; also see Al-Hashimi et al. [18]) }\end{array}$ \\
& & \\
& & \\
2. AMBN & Frameshift mutations in & \\
& $\begin{array}{l}\text { Chrysemys picta exons 6 and 11 } \\
\text { (Additional file 3) }\end{array}$ & $\begin{array}{l}\text { Frameshift mutations in Anas platyrhynchos } \\
\text { (exons 6, 8), Gallus gallus (exons 3, 6), and }\end{array}$ \\
& & $\begin{array}{l}\text { Taeniopygia guttata (exon 6); stop codon in } \\
\text { exon 8 of Melopsittacus undulatus (Additional } \\
\text { file 3) }\end{array}$
\end{tabular}

3. AMEL
Framshift mutations in Chrysemys picta (exon 1) and Pelodiscus sinensis (exons 1, 3, 4) (Additional file 7)
Frameshift mutations in Anas platyrhynchos (exons 1, 2, 3, 4), Gallus gallus (exons 1, 2, 4), Meleagris gallopavo (exons 1, 2), Melopsittacus undulatus (exons 1, 2), and Taeniopygia guttata (exons 2) (Additional file 7; also see Sire et al. [20] and Davit-Béal et al. [21])

\section{Mammals}

Frameshift mutations in exon 10 (homologous

to exon 9 of Alligator) of Tubulidentata

(aardvark), Pholidota (pangolins), Xenarthra (anteaters, sloths, armadillos), Mysticeti (baleen whales), and Kogiidae (pygmy and dwarf sperm whales) $[1,2]$

Frameshift mutations in exon 13 of seven baleen whales (Mysticeti) [1,3]; premature stop codon in exon 13 of Monodon monoceros [19]; multiple inactivating mutations in Orycteropus afer (stop codon in exon 5, complete deletion of exon 6, frameshift deletion in exon 13) (Additional file 5); acceptor splice site mutation in intron 2 of Choloepus hoffmanni (AG to AT)

Frameshift mutations in Choloepus hoffmanni (exons 2, 6), deletion of $3^{\prime}$ end of intron 6 (including splice site) and first $14 \mathrm{bp}$ of exon 7 in Dasypus novemcinctus, and two stop codons in exon 6 of Orycteropus afer (Additional file 11); frameshift mutations in exon 6 of five mysticetes $[1,3]$ 
The oldest testudines with unambiguous crown-group affinities, including tooth loss on the palatines, vomer, and pterygoids, are from the Late Jurassic [23].

To date, remnants of pseudogenized copies of toothspecific genes in Testudines have not been reported. Girondot and Sire [27] were unable to amplify fragments of amelogenin in turtles with degenerate PCR primers, and it remains unclear if vestiges of tooth-specific genes are retained in testudine genomes given the antiquity of tooth loss in this clade. On the other hand, phylogenomic data suggest that Testudines have slower rates of nuclear gene evolution than birds and mammals (fig. 1 in [28]). The recent release of two testudine genomes, Chrysemys picta (painted turtle) and Pelodiscus sinensis (Chinese softshell turtle), provides an opportunity to screen for remnants of tooth-specific genes in turtles. These taxa, both of which belong to Cryptodira (hidden neck turtles), index the basal cladogenic event among crown cryptodires and leave only Pleurodira (sideneck turtles) unrepresented among the three oldest crown-testudine lineages. Cryptodira and Pleurodira have traditionally been regarded as reciprocally monophyletic based on morphology [29-31] and large molecular data sets [32,33]. An exception is Barley et al.'s [32] coalescence analysis, which recovered a basal split between softshells plus the pig-nosed turtle (Carettochelys insculpta) and Pleurodira plus other Cryptodira. However, Barley et al.'s [32] concatenation analysis recovered Cryptodira and Pleurodira. Moreover, the most complete testudine phylogeny with a variety of outgroups [33] supports the monophyly of both Cryptodira and Pleurodira.

Here, we report the results of querying the genomes of Chrysemys and Pelodiscus for inactivated remnants of three EMP genes, ENAM, $A M E L$, and $A M B N$, all of which are hypothesized to have tooth-specific functions. We also report the results of querying genome sequences of five birds (Gallus gallus [chicken], Meleagris gallopavo [turkey], Taeniopygia guttata [zebra finch], Anas platyrhynchos [duck], Melopsittacus undulatus [budgerigar]) and three enamelless mammals (Orycteropus afer [aardvark], Choloepus hoffmanni [Hoffmann's two-toed sloth], Dasypus novemcinctus [nine-banded armadillo]) for remnants of these EMP genes. The occurrence of pseudogenized remnants of EMP genes in highly divergent amniotes, including turtles, birds, and edentulous/enamelless mammals, would provide robust evidence for the hypothesis that the only essential, non-redundant function of $A M E L, A M B N$, and $E N A M$ is in enamel formation. Moreover, the search for shared frameshift mutations in EMP genes provides an opportunity to date the timing of enamel loss in these clades.

\section{Methods}

The genomes of Chrysemys picta (painted turtle; PreEnsembl) and Pelodiscus sinensis (Chinese softshell turtle;
Ensembl 68) were queried with BLASTN using crocodylian mRNA sequences for three enamel matrix proteins genes: Paleosuchus palpebrosus (Cuvier's dwarf caiman) AMEL (AF095568), Caiman crocodilus (spectacled caiman) AMBN (AY043290), and Crocodylus niloticus (Nile crocodile) ENAM (GU344683). Intron-exon boundaries of mRNA sequences were determined by blasting crocodylian mRNAs against the recently released genome sequence of Alligator mississippiensis (American alligator). Crocodylian sequences were chosen as probes based on recent evidence that provides strong support for a sister group relationship between Testudines and Archosauria (crocodylians, birds) [27,34]. $A M B N$ has 11 exons in Alligator, all of which include protein-coding regions. $A M E L$ includes six exons in Alligator, five of which (1-5) contain protein-coding regions. Finally, ENAM includes nine exons in Alligator, eight of which (2-9) include protein-coding regions. Remnants of EMP genes that were recovered from Chrysemys were subsequently used to query the Pelodiscus genome, and remnants of EMP genes from Pelodiscus were used to query the Chrysemys genome. Five bird genomes (Anas platyrhynchos [duck], Gallus gallus [chicken], Meleagris gallopavo [turkey], Melopsittacus undulatus [budgerigar], Taeniopygia guttata [zebra finch]) were queried with crocodylian mRNAs and virtual pseudogene mRNAs for AMEL (EU340348) and ENAM (GU198360) from Gallus, as well as with positive hits from the initial round of screening for the bird genomes. The NCBI genomes of three enamelless mammals (Orycteropus afer [aardvark], Choloepus hoffmanni [Hoffmann's two-toed sloth], Dasypus novemcinctus [nine-banded armadillo]) were queried with gene sequences from mammals that retain enamelcapped teeth (i.e., Bos taurus, Homo sapiens, Echinops telfairi, Elephantulus edwardii, Trichechus manatus). Sequences were aligned with Se-Al [35].

Selection analyses on branches were performed with PAML 4.5 [36] to estimate $\mathrm{dN} / \mathrm{dS}$ values for an assemblage of 20 complete or nearly complete mammalian $A M B N$ sequences, all of which were derived from Ensembl 68 (Ailuropoda melanoleuca, Bos taurus, Callithrix jacchus, Equus caballus, Oryctolagus cuniculus) or NCBI (Canis lupus familiaris [XM_539304], Choloepus hoffmanni [ABVD01066982, TI 1336370099, ABVD01066984, TI 1338793682, TI 1368206053, ABVD01066985, ABVD01066986], Dasypus novemcinctus [AAGV03237582], Echinops telfairi [AAIY02097297, AAIY02097298], Elephantulus edwardii [AMGZ01205754, AMGZ01205755], Homo sapiens [NM_016519], Loxodonta africana [AAGU03054364, AAGU03054363], Orycteropus afer [ALYB01124783], Pan paniscus [XM_001160377], Pan troglodytes [XM_001160377], Pongo abelii [XM_002814835], Procavia capensis [ABRQ01419216, ABRQ01419217, ABRQ01419218, ABRQ01419219, ABRQ01419220], Sus scrofa [NM_214037]). Sequences were aligned with Se-Al [35]. Branch analyses 
were performed with four branch categories: Orycteropus, Choloepus, Dasypus, and all other branches. Orycteropus, Choloepus and Dasypus were recognized as separate branches in the PAML runs based on the hypothesized independent loss of enamel in these lineages [2]. PAML analyses were conducted with codon frequency models 1,2 , and 3. We used a composite species tree based on Meredith et al. [37] and Springer et al. [38]. Approximate divergence dates and fossil ages in Figure 1 are taken from the following sources: Amniota and Testudines to Archosauria [39]; Pelodiscus to Chrysemys [40]; Odontochelys [25]; Neognathae [41]; Galloanserae and Gallus to Meleagris [42]; Taeniopygia to Melopsittacus [43]; Ichthyornis [44]; Xenarthra [45]; Xenarthra to Orycteropus [37]; Eomaia [46].

\section{Results}

\section{ENAM Gene}

Blast searches with Crocodylus niloticus (Nile crocodile) ENAM (GU344683) identified almost the entirety of exon 9 in Chrysemys picta (Additional file 1). Remnants of this exon in C. picta were identified on scaffold JH584398, which has not yet been mapped onto a chromosome. The ENAM sequence for exon 9 in Chrysemys includes numerous frameshift indels (Figure 1, Table 2, Additional files 1,2), one of which is a SINE insertion that shares homology with members of the Cry family of SINEs in Cryptodira [47] (Additional files 1, 2). An additional SINE insertion occurs 3' to the stop codon. Remnants of exon 9 in Chrysemys comprise $\sim 3840$ bp after excluding the SINE insertions. Chrysemys exon 9 retains a "TAA" stop codon in the same location as Crocodylus. By contrast with the results of blast searches against the Chrysemys genome, blast searches with Crocodylus ENAM resulted in no significant hits to the Pelodiscus sinensis genome. Likewise, blast searches with the recovered ENAM pseudogene segment from Chrysemys did not find significant matches in the Pelodiscus genome.

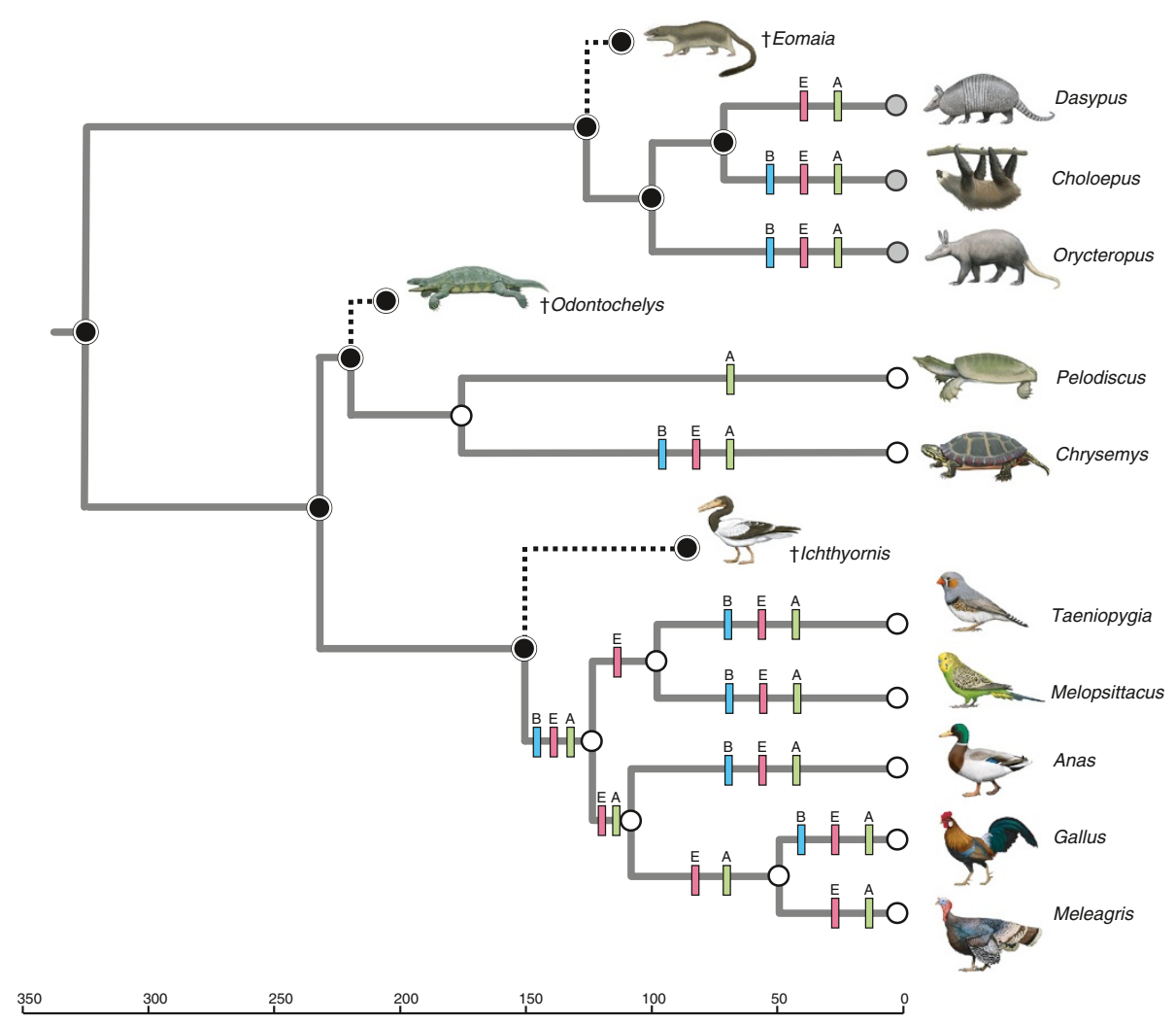

Figure 1 Timetree of edentulous and enamelless amniote taxa for which genomic sequences are available (Ensembl, PreEnsembl, NCBI) with a mapping of inferred inactivating mutations (frameshifts, premature stop codons, splice site mutations) in three EMP genes to particular branches in the tree. Branches with inactivating mutations are marked by vertical bars (pink $=E N A M[E]$, blue $=A M B N[B]$, green $=$ AMEL $[A]$ ). Extinct stem taxa with teeth (Odontochelys, Ichthyornis, Eomaia) are also shown. Mutations were mapped to branches by Fitch parsimony with delayed transformation optimization. Teeth with enamel, teeth without enamel, and edentulism are denoted with black, gray, and white-filled circles, respectively, at terminal and internal nodes. In combination with fossil evidence, dN/dS ratios and frameshift mutations in ENAM suggest that enamel was lost independently in the common ancestor of Pilosa (sloths and anteaters) and in multiple armadillo lineages, including Dasypus [2]. Remnants of AMBN and ENAM were not recovered from the Pelodiscus genome. References for divergence dates and fossil ages are provided in Methods. 
Table 2 Examples of inactivating mutations in enamel matrix protein genes among edentulous and enamelless amniotes with genome sequences

\begin{tabular}{|c|c|c|c|}
\hline \multirow[t]{2}{*}{ Taxon } & \multicolumn{3}{|l|}{ Inactivating mutations } \\
\hline & ENAM & $A M B N$ & AMEL \\
\hline Cryptodira & None & None & Possible shared frameshift mutations in exon 2 (see AF9) \\
\hline \multirow[t]{2}{*}{ Chrysemys } & $\begin{array}{l}\text { AF1 Insertions: 65, 271, 411, 485, } \\
\text { 994-1138 (Cry), 2526-2529, 2559- } \\
\text { 2571, } 3268\end{array}$ & $\begin{array}{l}\text { AF3 Insertions: 956-957, 972, } \\
\text { 1051-1052 }\end{array}$ & AF7 Deletion: 106 \\
\hline & $\begin{array}{l}\text { AF1 Deletions: 588, 1264-1276, } \\
\text { 3325-3343 }\end{array}$ & $\begin{array}{l}\text { AF3 Deletions: 497-498, 605-611, } \\
\text { 794-804, 984-985 }\end{array}$ & \\
\hline Pelodiscus & Gene not recovered & Gene not recovered & AF7 Deletions: 122-125, 208, 271, 276 \\
\hline \multirow[t]{2}{*}{ Neognathae } & $\begin{array}{l}\text { AF1 Insertions: 1985-1989, 2143- } \\
\text { 2144, }\end{array}$ & AF3 Deletion: 515-524 & $\begin{array}{l}\text { AF7 Deletions: } 134 \text { (with subsequent deletion of one additional } \\
\text { bp in Taeniopygia), } 242,709-710\end{array}$ \\
\hline & $\begin{array}{l}\text { AF1 Deletions: 2634-2637, 3353- } \\
3758\end{array}$ & & \\
\hline Galloanserae & AF1 Deletion: 1189-1192 & None & AF7 Deletions: 173-174, 282-289 \\
\hline \multirow[t]{2}{*}{ Anas } & $\begin{array}{l}\text { AF1 Insertions: 552-562, 2031- } \\
2040\end{array}$ & $\begin{array}{l}\text { AF3 Deletions: 216-217, 226, } \\
455,727-728\end{array}$ & AF7 Insertions: 152, 181 \\
\hline & AF1 Deletions: 2626-2627 & & AF7 Deletion: 88-94 \\
\hline \multirow{2}{*}{$\begin{array}{l}\text { Gallus }+ \\
\text { Meleagris }\end{array}$} & AF1 Insertion: 2654 & None & AF7 Insertion: 484 \\
\hline & AF1 Deletion: 3263-3267 & & \\
\hline \multirow[t]{2}{*}{ Gallus } & AF1 Insertions: 512, 930-931 & AF3 Insertions: 225, 230 & AF7 Deletion: 275-276 \\
\hline & AF1 Deletions: 126-127, 585-595 & & \\
\hline Meleagris & AF1 Insertion: 2438-2441 & Gene not recovered & AF7 Deletion: 359 \\
\hline $\begin{array}{l}\text { Taeniopygia } \\
+ \\
\text { Melopsittacus }\end{array}$ & AF1 Deletion: 2958 & None & None \\
\hline Taeniopygia & AF1 Deletion: 3318 & AF3 Deletions: 578, 612-613 & AF7 Deletions: $378,407-417$ \\
\hline \multirow[t]{2}{*}{ Melopsittacus } & AF1 Insertions: 231, 2239 & AF3 Stop codon: 708-710 & AF7 Insertion: 105 \\
\hline & $\begin{array}{l}\text { AF1 Deletions: 432-433, 452-453, } \\
\text { 504-505 }\end{array}$ & & AF7 Deletions: 91-94, 387 \\
\hline Dasypus & See Meredith et al. [2] & None & $\begin{array}{l}\text { AF11 Deletion: } 3^{\prime} \text { end of intron } 6 \text {, including the acceptor splice } \\
\text { site, and the first } 14 \text { bp of exon } 7(665-678) \text {, which includes the } \\
\text { last amino acid and the stop codon }\end{array}$ \\
\hline \multirow[t]{3}{*}{ Choloepus } & \multirow[t]{3}{*}{ See Meredith et al. [2] } & \multirow{3}{*}{$\begin{array}{l}\text { Splice site mutation: AG to AT } \\
\text { at intron } 2 \text { acceptor site (gb|ti| } \\
\text { 1338556193) }\end{array}$} & AF11 Deletions: $45-55,600$ \\
\hline & & & AF11 Initiation codon mutation: ATG to ACG (13-15) \\
\hline & & & AF11 Stop codon: $356-358$ \\
\hline \multirow[t]{2}{*}{ Orycteropus } & \multirow[t]{2}{*}{ See Meredith et al. [2] } & $\begin{array}{l}\text { AF5 Deletions: } 415-651 \text { (all of } \\
\text { exon 6), 1241-1253 }\end{array}$ & AF11 Stop codons: 239-241, 299-301 \\
\hline & & AF5 Stop codon: $388-390$ & \\
\hline
\end{tabular}

Numbers correspond to sequence alignment positions in Additional files. Additional file $1=$ AF1; Additional file $3=$ AF3; Additional file $5=$ AF5; Additional file 7 = AF7; Additional file 9 = AF9; Additional file $11=$ AF11. Cry = Cry SINE [47].

Blast searches with the virtual pseudogene mRNA of Gallus ENAM exon 9 recovered homologous fragments of this exon in Meleagris gallopavo (turkey), Taeniopygia guttata (zebra finch), Anas platyrhynchos (duck), and Melopsittacus undulatus (budgerigar). The 3' region of M. gallopavo ENAM was recovered on chromosome 1, whereas the 5 ' region was recovered on the $\mathrm{Z}$ chromosome of this species. All of the exon 9 sequences were characterized by frameshift mutations (Figure 1), including a 406 bp deletion near the 3' end of the coding sequence of exon 9 that is shared by all five birds (Additional file 1).

ENAM sequences for Orycteropus afer, Choloepus hoffmanni and Dasypus novemcinctus were reported by Meredith et al. [2] and are not duplicated here. Orycteropus ENAM includes three frameshift mutations [2]. Among xenarthrans, Choloepus ENAM includes numerous frameshift mutations whereas Dasypus ENAM includes a single frameshift mutation that is located near the carboxy- 
terminal end of the coding sequence in exon 10 (= exon 9 of some non-mammalian vertebrates) [2].

\section{AMBN Gene}

Blast searches with Caiman crocodilus (spectacled caiman) $A M B N$ (AY043290) recovered portions of exons 1, 2, 3, 6, 8, 9, 10, and 11, in this order, on Chrysemys scaffold JH584398 (Additional files 3 and 4). The AMBN exons are located immediately upstream of ENAM exon 9 on scaffold JH584398. Frameshift mutations occur in exons 6, 10, and 11 (Figure 1, Table 2, Additional files 3, 4). AMBN sequences were not found in Pelodiscus.

Among birds, remnants of $A M B N$ were discovered in Anas (scaffold 247: exons 2, 3, 5, 6, 7, 8), Gallus ( $\mathrm{Z}$ chromosome: exons 2, 3, 5, 6), Taeniopygia (Z chromosome; exons 6, 7, 8), and Melopsittacus (scaffold JH556633: exons 7, 8). Frameshift mutations occur in Anas (exons 2, 6, 8), Gallus (exon 3) and Taeniopygia (exon 6) (Additional file 3). A ten-bp frameshift deletion is shared by Anas, Gallus, and Taeniopygia, which together index the common ancestry of Neognathae, although this region was not recovered in Meleagris and Melopsittacus. There were no frameshifts in Melopsittacus exons 7 and 8, but a stop codon occurs in the latter exon.

Among mammals, we recovered exons 1-5, 7, and 10-13 in Orycteropus afer (Additional file 5). Exon 5 contains a stop codon and there is a 13-bp frameshift deletion in exon 13 (Table 2). Exon 6 has been deleted along with portions of introns 5 and 6 (Table 2). Exons 8 and 9 are 39-bp duplications of exon 7 that occur in primates [48] and their absence in Orycteropus is not unexpected. With the exception of Elephantulus edwardii, which has two duplications of exon 7 as in Homo, other afrotherians (Loxodonta africana, Trichechus manatus, Procavia capensis, Chrysochloris asiatica, Echinops telfairi) are similar to Orycteropus in possessing only exon 7 . We also recovered sequences for exons 1-7 and 10-13 in Dasypus AMBN (Additional file 5). The recovered protein-coding sequence is intact, although the presumed start codon is ten codons downstream of the start codon in the human sequence and occurs in exon 2 rather than exon 1, as is also the case for Loxodonta africana (African elephant) (Additional file 6). Complete coding sequences for nine exons $(1-5,7,10-12)$ and partial sequences for exons 6 and 13 were recovered from the Choloepus genome (Additional file 5). The putative start codon in Choloepus is located in exon 2 as in Dasypus. There are no frameshift mutations or stop codons in the available Choloepus sequence, but intron 2 exhibits an inactivating mutation at the acceptor splice site (AG to AT; see TI\# 1338556193 in Trace Archives) (Table 2). By contrast, all of the donor and accepter splice sites exhibit canonical GT and AG motifs, respectively, in 16 mammals with enamelcapped teeth (taxon names provided in Methods).
Selection analyses based on an alignment of 20 mammalian $A M B N$ sequences (Additional file 6) with codon frequency (CF) models 1,2 , and 3 all suggest elevated $\mathrm{dN} / \mathrm{dS}$ ratios on the Orycteropus $(\mathrm{CF} 1=0.71, \mathrm{CF} 2=0.77, \mathrm{CF} 3=$ 0.89), Choloepus (CF1 $=0.86, \mathrm{CF} 2=0.90, \mathrm{CF} 3=1.04)$ and Dasypus $(\mathrm{CF} 1=0.64, \mathrm{CF} 2=0.71, \mathrm{CF} 3=0.74)$ branches relative to the background rate $(\mathrm{CF} 1=0.48, \mathrm{CF} 2=0.51$, CF3 $=0.56)$ in mammalian taxa with enamel-covered teeth.

\section{AMEL Gene}

Blast searches with Paleosuchus palpebrosus (Cuvier's dwarf caiman) AMEL (AF095568) recovered most of exons 1, 3, 4, and 5 in Pelodiscus, with ancestral synteny preserved, on scaffold JH208023 (Additional files 7 and 8). Exons 1 and 5 were identified on scaffold JH584884 in Chrysemys (Additional files 7 and 8). Chrysemys and Pelodiscus both retain the same start codon as in crocodylians. Frameshift mutations are present in sequences of both testudine species (exon 1 in Chrysemys, exons 1, 3, and 4 in Pelodiscus), although there are no shared frameshifts in these two exons (Figure 1, Table 2, Additional files 7 and 8). In addition, Pelodiscus and Chrysemys share exonflanking sequences that are 3' to exon 1 and 5' to exon 5. The sequence that flanks exon 1 is $>1000 \mathrm{bp}$ and includes regions that are homologous to intron 1 and possibly exon 2 of Alligator mississippiensis (Additional file 6). Intron 1 retains the canonical "GT" splice donor site in both testudines (Additional file 9). The homology of exon 2 is less certain, but nevertheless of potential importance as there are multiple shared frameshift mutations in Chrysemys and Pelodiscus (Additional file 9). The sequence that flanks exon 5 is $>600$ bp long and is homologous to a portion of intron 4 of $A$. mississippiensis with the canonical "AG" splice acceptor site in Chrysemys ("AA" in Pelodiscus) (Additional file 10).

In birds, blast searches with Gallus AMEL pseudogene mRNA (EU340348) recovered homologous DNA sequences in Anas (exons 1-4 with original synteny on scaffold 415), Meleagris (exons 1-4 with original synteny on chromosome 1), Melopsittacus (exons 1-4 with original synteny on AGAI01063440), and Taeniopygia (exons 2-4 with original synteny on chromosome 1) (Additional file 7). All of the birds except for Anas share a common start codon with crocodylians. Frameshift mutations occur in all avian taxa, including a one-bp deletion in exon 4 that is shared by all five birds (Figure 1).

Among mammals, there are two stop codons in exon 6 of Orycteropus AMEL (Figure 1, Table 2, Additional file 11). Choloepus $A M E L$ shows replacement of the methionine initiation codon in exon 2 by a threonine codon, an $11 \mathrm{bp}$ frameshift deletion in exon 2, and a premature stop codon followed by a frameshift deletion in exon 6 (Figure 1, Table 2, Additional file 11). All of 
the inactivating mutations in Choloepus are corroborated by chromatograms in NCBI's Trace Archives. The sequence for Dasypus is intact through exon 6 (excepting exon 4, see below), but a deletion incorporates the 3 ' end of intron 6, including the acceptor splice site, and the first 14 bp of exon 7, including the stop codon. Orycteropus, Choloepus, and Dasypus also lack a functional copy of exon 4, either because of stop codons (Orycteropus, Choloepus) or a donor splice site mutation (GT to AT) in intron 4 that is adjacent to this exon. However, a functional copy of exon 4 is variably present in Mammalia [48] and is missing from six other afrotherians (Chrysochloris, Echinops, Elephantulus, Loxodonta, Procavia, Trichechus) with genome sequences because of stop codons, frameshift mutations, and/or splice site mutations (data not shown).

\section{Discussion}

\section{EMP Genes in Turtles}

Crown Testudines comprise 319 extant species [49], all of which are toothless and instead have a keratinized beak that in combination with strong jaw muscles allows testudines to tear food and capture prey [21]. The oldest testudine fossil is the Late Triassic Odontochelys semitestacea from China [25]. Odontochelys lacked a beak and instead retained both marginal and palatal teeth [25]. Proganochelys quenstedti is also known from the Late Triassic, and is more derived than Odontochelys. Proganochelys lacked marginal teeth, but palatal teeth were present. The morphology of the mandibles suggests that Proganochelys possessed a keratinized beak [26]. It remains unclear if palatal teeth, which occur on the vomer, palatine, and pterygoid bones, were lost in the common ancestor of all living turtles or independently in cryptodires and pleurodires owing to alternate phylogenetic hypotheses wherein taxa with palatal teeth such as Kayentachelys apix are positioned as stem testudines or as stem cryptodires [23,24,29$31,50,51]$. In either case palatal teeth were lost no later than the Late Jurassic in the ancestry of crown testudines.

The retention of pseudogenized copies of three EMP genes (AMEL, AMBN, ENAM) in Chrysemys is perhaps surprising given the antiquity of tooth loss in turtles and the extended time window for large-scale deletions and/or rearrangements to erase or scramble the genomic instructions for enamel production in this edentulous taxon. However, remnants of $A M B N$ and $E N A M$ exon 9 in Chrysemys occur in juxtaposition to each other on the same contig. Kawasaki's [52] reconstructions of SCPP gene order in both stem tetrapods and stem amniotes suggest that $A M B N$ is immediately upstream of ENAM. Thus, it appears that remnants of this original gene order are present in the painted turtle genome. The protein-coding regions of $A M B N$ and ENAM in Chrysemys have been battered by inactivating mutations, including SINE insertions in exon 9 of ENAM, but nevertheless retain unambiguous signatures of their heritage. The only EMP gene that was recovered in Pelodiscus is $A M E L$. It remains unclear whether $A M B N$ and $E N A M$ were completely deleted from the Pelodiscus genome during evolutionary history, are difficult to recognize because of numerous mutations, or are missing from the current assembly of the Pelodiscus genome due to incomplete sequencing assembly. Pelodiscus $A M E L$ is relatively complete and includes exons $1,3,4$, and 5 in their original syntenic order. By contrast, we only discovered exons 1 and 5 of Chrysemys AMEL. The two exons represent the only overlapping EMP fragments that were discovered in both Pelodiscus and Chrysemys. Frameshift mutations in $A M E L$ occur in both species, but the only shared frameshift mutations occur in putative exon 2 , which has equivocal homology with the same exon in crocodylians. Nevertheless, if these frameshift mutations are genuine then there is molecular evidence for the inactivation of enamel production in the common ancestry of Cryptodira.

The genetic and developmental basis of edentulism in turtles involves both tooth-specific and pleiotropic genes. Results presented here demonstrate that three toothspecific EMP genes were pseudogenized in the ancestry of modern cryptodires. Previously, Tokita et al. [53] examined patterns of gene expression in the developing lower jaw of Pelodiscus sinensis and reported impairment of Shh signaling in the oral epithelium along with early-stage arrest of odontoblast development by abrogation of $M s \times 2$ expression in dental mesenchyme. It remains unclear if changes in gene expression or EMP pseudogenization occurred first in the evolutionary history of turtles.

\section{EMP Genes in Birds}

$A M E L$ and ENAM pseudogenes have previously been reported in Gallus [20], which belongs to Galliformes. We provide extended evidence for inactivated EMP genes in birds and show that there are remnants of $A M E L$ and $E N A M$ in four other birds with complete genome sequences: Meleagris (Galliformes), Anas (Anseriformes), Melopsittacus (Psittaciformes), and Taeniopygia (Passeriformes) (Table 1). In addition, we recovered molecular evidence for an inactivated copy of $A M B N$ in Anas, Gallus, Taeniopygia, and Melopsittacus. It is noteworthy that there are putative frameshift mutations in $A M B N, A M E L$, and ENAM that are shared by representatives of Galliformes (Gallus, Meleagris), Anseriformes (Anas), and Neoaves (Taeniopygia, Melopsittacus), which together index the deepest split in Neognathae [54]. It will be important to determine if these inactivating mutations are shared with Palaeognathae (tinamous and ratites), in which case molecular evidence would be consistent with the loss of enamel in the common ancestor of Neornithes rather than independently in Neognathae and Palaeognathae. 


\section{EMP Genes in Mammals}

It has previously been shown that ENAM is a pseudogene in a wide array of edentulous and enamelless mammals $[1,2]$ (Table 1). Further, $A M E L$ and $A M B N$ sequences have been reported for baleen whales and in both cases are inactivated in multiple species $[1,3]$. However, the functional versus pseudogene status of $A M E L$ and $A M B N$ remains to be investigated in most edentulous and enamelless taxa.

Here, we provide evidence of inactivating mutations in AMEL in Orycteropus afer (aardvark) and Choloepus hoffmanni (Hoffmann's two-toed sloth), both of which have enamelless teeth comprised of dentin. Multiple frameshift mutations in Choloepus AMEL are confirmed by Trace Archives chromatograms (Additional file 8). The two stop codons in Orycteropus are based on Illumini $\mathrm{Hi}$-Seq sequencing technology with $44 \mathrm{X}$ genome coverage.

Previous studies suggest that $A M B N$ may play a role in dentin formation/regeneration [55,56]. However, this hypothesis is contradicted by our finding that there are inactivating mutations in Orycteropus and Choloepus $A M B N$. Moreover, $\mathrm{dN} / \mathrm{dS}$ ratios indicate relaxed purifying selection in these taxa. Similarly, McGowen [19] reported a premature stop codon in exon 13 (JF504758) of Monodon monoceros (narwhal). Narwhals have vestigial teeth, and in the case of males a single enlarged tusk. Both the vestigial teeth and tusk are composed of dentin and cementum, but no enamel [57-59]. The occurrence of a premature stop codon in Monodon AMBN, in conjunction with inactivating mutations in two other lineages with enamelless teeth (Orycteropus, Choloepus), is consistent with the hypothesis that the only essential, non-redundant role of $A M B N$ is in enamel formation. Along these lines, ameloblastin knockout mice do not form an enamel layer, and lack dentin defects $[13,15]$.

By contrast with Choloepus, where enamel loss occurred more than 50 million years ago, enamel degeneration in Dasypus occurred more recently [2]. Dasypus retains a vestigial enamel or enamel-like substance that covers the dentin of some teeth and is quickly worn off. Moreover, there are no frameshifts in ENAM that are shared by Dasypus and other armadillo genera [2]. The single frameshift in Dasypus ENAM precludes a functional, full-length enamelin protein, but the location of the frameshift is close to the 3' end of the protein-coding sequence in exon 10 , and shorter protein products are possible [2]. Our finding that $A M B N$ is intact in Dasypus, and that only the last amino acid is truncated from the coding region of $A M E L$, is consistent with the presence of vestigial 'enamel' in this species [2]. We also note that a partial $A M B N$ sequence (JF701624) for Kogia breviceps (pygmy sperm whale) has an intact protein-coding region even though $K$. breviceps has enamelless teeth and frameshift mutations in the ENAM gene. It will be important in future studies to sequence the remaining exons of Kogia $A M B N$ to determine if the missing exonic regions contain frameshift mutations and/or other inactivating mutations.

\section{Conclusions}

Edentulism has evolved independently in multiple lineages of living amniotes including turtles, birds, echidnas, baleen whales, anteaters, and pangolins. There are also mammals with enamelless teeth including pygmy sperm whale, narwhal, sloths, armadillos, and aardvarks. In every case these edentulous or enamelless forms have descended from ancestors with enamel-capped teeth. Thus, amniote diversity provides a natural laboratory for testing hypotheses of tooth-specific gene function [3]. Moreover, this laboratory includes multiple, replicated experiments. $A M B N, A M E L$, and $E N A M$ have all been postulated to have tooth-specific or even enamel-specific gene functions [11-17], although pleiotropic functions have been suggested for $A M B N[9,48,60,61]$ and $A M E L[62,63]$. The widespread occurrence of EMP pseudogenes in turtles, birds, and several mammalian lineages (Table 1) provides compelling evidence that the only unique, non-redundant function of these genes in amniotes is in enamel formation: functional copies of these genes have not been retained by natural selection when enamel production was abrogated independently in distantly related lineages. By contrast, representative sequences from amniotes with enamel-capped teeth retain intact coding sequences for $A M B N[1,48]$; also see Additional file 11, AMEL [3,48,64], and ENAM [1,2,18,37,65].

The evolution of tooth loss in multiple amniote lineages also provides a model system for integrating the fossil record, phylogenetics, and genomics. This system allows for reciprocal hypothesis testing and provides a multifaceted, synthetic view on macroevolutionary transitions in testudines, birds, and edentulous/enamelless mammals $[1,2]$. The fossil record and phylogenetics combine to predict the occurrence of molecular fossils of tooth-specific genes in the genomes of edentulous and enamelless amniotes, and molecular fossils have been discovered in all lineages that have been investigated. We suggest that these striking patterns may prove especially useful for educating the public on the convergence of evidence that clearly documents the evolutionary process over deep time.

\section{Additional files}

Additional file 1: Nexus alignment of ENAM exon 9 sequences for two crocodylians, one testudine, and five birds. The stop codon in crocodylians and Chrysemys picta occurs at positions 3788-3790. A 406 bp deletion that is shared by all five birds occurs near the $3^{\prime}$ end of the coding region at positions 3353-3758. Additional frameshift mutations are shared by four of five birds including representatives of Anseriformes, Galliformes, and Passeriformes (2634-2637). Cry SINE elements [47] in Chrysemys occur at 
positions 994-1138 and 4782-4994. Several long strings of Ns in Chrysemys picta were abridged to shorter strings of ten Ns.

Additional file 2: Schematic alignment showing regions of ENAM exon 9 that were identified in Chrysemys picta. Green bars below sequence numbers show regions of sequence similarity between $C$. picta and Alligator mississippiensis. Red rectangles $=$ frameshift mutations in $C$. picta; light blue rectangles $=$ indels within the coding sequence that are in multiples of three base pairs; $C R Y=$ Cry SINE insertion; red arrow = position of stop codon in A. mississippiensis.

Additional file 3: Nexus alignment of $A M B N$ exon sequences for two crocodylians, one testudine, and one bird. The start and stop codons in crocodylians occur at positions 127-129 (exon 2) and 13741376 (exon 11), respectively.

Additional file 4: Schematic alignment showing regions of $A M B N$ exons 1-11 that were identified in Chrysemys picta. Green bars below sequence numbers show regions of sequence similarity between $C$. picta and Alligator mississippiensis. Dark blue rectangles = numbered exons in A. mississippiensis; red rectangles $=$ frameshift mutations in C. picta; light blue rectangles $=$ indels within the coding sequence that are in multiples of three bp; dark blue arrow $=$ position of start codon in $A$. mississippiensis; red arrow $=$ position of stop codon in A. mississippiensis.

Additional file 5: Nexus alignment of $A M B N$ exon sequences for Homo sapiens, Orycteropus afer and six other afrotherians, Dasypus novemcinctus, and Choloepus hoffmanni. The start and stop codons in Homo occur at positions 121-123 (exon 1) and 1468-1470 (exon 13), respectively. The presumed start codon in Dasypus occurs at positions 151153. Dasypus shares the same stop codon as Homo at positions 1468-1470, whereas the presumed stop codon in Choloepus is at positions 1477-1479.

Additional file 6: Nexus alignment of protein-coding AMBN sequences for 20 mammals that was used in selection analyses with PAML 4.5 [36].

Additional file 7: Nexus alignment of AMEL exon sequences in nexus format for two crocodylians, two testudines, and five birds. The start and stop codons in crocodylians occur at positions 69-71 (exon 1) and 731733 (exon 5), respectively. A putative one-bp frameshift deletion that is shared by all five birds species occurs at position 242 in exon 4.

Additional file 8: Schematic alignment showing regions of $A M E L$ exons 1-5 that were identified in Chrysemys picta and Pelodiscus sinensis. Bars below sequence numbers show regions of sequence similarity between Alligator mississippiensis and both testudines (green) or A. mississippiensis and one testudine (chartreuse). Dark blue rectangles $=$ numbered exons in A. mississippiensis; red rectangles = frameshift mutations in C. picta; light blue rectangles $=$ indels within the coding sequence that are in multiples of three bp; dark blue arrow = position of start codon in $A$. mississippiensis; red arrow = position of stop codon in A. mississippiensis.

Additional file 9: Nexus alignment of Alligator mississippiensis AMEL exon 1 (positions 1-114), intron 1 (positions 115-813), and exon 2 (838-894) with exon 1 and flanking sequences from Chrysemys picta and Pelodiscus sinensis.

Additional file 10: Nexus alignment of AMEL intron 4 (positions 1662) and exon 5 (positions 663-844) sequences for Chrysemys picta and Pelodiscus sinensis.

Additional file 11: Nexus alignment of AMEL sequences (exons 2-7) for Homo sapiens, Orycteropus afer and six other afrotherians (Echinops telfairi, Chrysochloris asiatica, Elephantulus edwardii, Trichechus manatus, Loxodonta africana, Procavia capensis), Dasypus novemcinctus, and Choloepus hoffmanni. The start and stop codons in Homo occur at positions 13-15 (exon 2) and 668-670 (exon 7), respectively. The mutated stop codon and frameshift mutation in exon 2 of Choloepus are clear in gnl|ti|1325289135 and gn||ti|1311883086. The stop codon in exon 4 of Choloepus is confirmed by traces gn||ti|1325336699 and gn||ti| 1312095734. The frameshift mutation in exon 6 of Choloepus is evident in trace gnlltil1363579107. The deletion that includes the $3^{\prime}$ region of intron 6 and first 14 bp of exon 7 in Dasypus is evident in gn|ti| 1886397515.

\section{Competing interests}

The authors declare that they have no competing financial interests.
Authors' contributions

JG, RWM, and MSS conceived and designed the study. RWM and MSS performed the analyses. MSS wrote the manuscript. JG and RWM provided comments on the manuscript. JG and MSS prepared figures. All authors read and approved the final manuscript.

\section{Acknowledgements}

This work was supported by NSF (EF0629860 to MSS and JG; DEB0743724 to $J G)$. We thank four anonymous referees for helpful comments on an earlier draft of this manuscript.

\section{Author details}

1'Department of Biology, University of California, Riverside, CA 92521, USA. ${ }^{2}$ Current address: Department of Biology and Molecular Biology, Montclair State University, Montclair, NJ 07043, USA.

Received: 30 October 2012 Accepted: 16 January 2013 Published: 23 January 2013

\section{References}

1. Deméré TA, McGowen MR, Berta A, Gatesy J: Morphological and molecular evidence for a stepwise evolutionary transition from teeth to baleen in mysticete whales. Syst Biol 2008, 57:15-37.

2. Meredith RW, Gatesy J, Murphy WJ, Ryder OA, Springer MS: Molecular decay of the tooth gene enamelin (ENAM) mirrors the loss of enamel in the fossil record of placental mammals. PLoS Genet 2009, 5:e1000634.

3. Meredith RW, Gatesy J, Cheng J, Springer MS: Pseudogenization of the tooth gene enamelysin (MMP20) in the common ancestor of extant baleen whales. Proc R Soc B 2011, 278:993-1002.

4. Scarel-Caminaga RM, Pasetto S, da Silva ER, Peres RCR: Genes and tooth development: reviewing the structure and function of some key players. Braz J Oral Sci 2003, 2:339-347.

5. Chai Y, Maxson RE Jr: Recent advances in craniofacial morphogenesis. Dev Dynamics 2006, 235:2353-2375.

6. Thesleff I: The genetic basis of tooth development and dental defects. Am J Med Gen 2006, 140A:2530-2535.

7. Kapadia H, Mues G, D'Sousa R: Genes affecting tooth morphogenesis. Orthod Craniofacial Res 2007, 10:105-113.

8. Bei M: Molecular genetics of tooth development. Curr Opin Gen Dev 2009, 19:504-510.

9. Catón J, Tucker AS: Current knowledge of tooth development: patterning and mineralization of the murine dentition. J Anat 2009, 214:502-515.

10. Fleischmannova J, Matalova E, Tucker AS, Sharpe PT: Mouse models of tooth abnormalities. Eur J Oral Sci 2008, 116:1-10.

11. Snead ML, Lau EC, Zeichner-David M, Fincham AG, Woo SLC, Slavkin HC DNA sequence for cloned CDNA for murine amelogenin reveal the amino acid sequence for enamel-specific protein. Biochem Biophys Res Comm 1985, 129:812-818.

12. Rajpar MH, Harley K, Laing C, Davies RM, Dixon MJ: Mutation of the gene encoding the enamel-specific protein, enamelin, causes autosomaldominant amelogenesis imperfecta. Hum Mol Gen 2001, 10:1673-1677.

13. Fukumoto S, Kiba T, Hall B, lehara N, Nakamura T, Longenecker G, Krebsbach PH, Nanci A, Kulkarni AB, Yamada Y: Ameloblastin is a cell adhesion molecule required for maintaining the differentiation state of ameloblasts. J Cell Biol 2004, 167:973-983.

14. Fukumoto S, Arakaki M, Iwamoto T, Yamada A, Miyamoto R, Naruse M, Nakamura T: Epithelial cell lines in the field of dental research: review. In Interface of Oral Health Science 2011. Edited by Sasaki K, Suzuki O, Takahashi N. New York: Springer; 2012:327-333.

15. Hu JC-C, Hu Y, Smith CE, McKee MD, Wright JT, Yamakoshi Y, Papagerakis P, Hunter GK, Feng JQ, Yamakoshi F, Simmer JP: Enamel defects and ameloblast-specific expression in Enam knock-out/lacZ knock-in mice. J Biol Chem 2008, 283:10858-10871

16. Hatakeyama J, Fukumoto S, Nakamura T, Haruyama N, Suzuki S, Hatakeyama Y, Shum L, Gibson CW, Yamada Y, Kulkarni AB: Synergistic roles of amelogenin and ameloblastin. J Dent Res 2009, 88:318-322.

17. Chan H-C, Estrella NMRP, Milkovich RN, Kim J-W, Simmer JP, Hu JC-C: Target gene analyses of 39 amelogenesis imperfecta kindreds. Eur J Oral Sci 2011, 119(Suppl 1):311-323.

18. Al-Hashimi N, Lafont A-G, Delgado S, Kawasaki K, Sire J-Y: The enamelin genes in lizard, crocodile, and frog and the pseudogene in the chicken 
provide new insights on enamelin evolution in tetrapods. Mol Biol Evol 2010, 27:2078-2094.

19. McGowen MR: Toward the resolution of an explosive radiation - a multilocus phylogeny of oceanic dolphins (Delphinidae). Mol Phylogenet Evol 2011, 60:345-357.

20. Sire J-Y, Delgado SC, Girondot M: Hen's teeth with enamel cap: from dream to impossibility. BMC Evol Biol 2008, 8:246.

21. Davit-Béal T, Tucker AS, Sire J-Y: Loss of teeth and enamel in tetrapods: fossil record, genetic data and morphological adaptations. J Anat 2009, 214:477-501.

22. Louchart A, Viriot L: From snout to beak: the loss of teeth in birds. Trends Ecol Evol 2011, 26:663-673.

23. Joyce WG: Phylogenetic relationships of Mesozoic turtles. Bull Peabody Mus Nat Hist 2007, 48:3-102.

24. Anquetin J, Barrett PM, Jones MEH, Moore-Fay S, Evans SE: A new stem turtle from the Middle Jurassic of Scotland: new insights into the evolution and palaeoecology of basal turtles. Proc Roy Soc B 2009, 276:879-886.

25. Li C, Wu X-C, Rieppel O, Wang L-T, Zhao L-J: An ancestral turtle from the Late Triassic of southwestern China. Nature 2008, 456:497-501.

26. Gaffney ES: The comparative osteology of the Triassic turtle Proganochelys. Bull Amer Mus Nat Hist 1990, 194:1-263.

27. Girondot M, Sire J-Y: Evolution of the amelogenin gene in toothed and toothless vertebrates. Eur J Oral Sci 1998, 106(Suppl 1):501-508.

28. Chiari Y, Cahais V, Galtier N, Delsuc F: Phylogenomic analyses support the position of turtles as the sister group of birds and crocodiles (Archosauria). BMC Biol 2012, 10:65

29. Gaffney ES, Hutchison JH, Jenkins FA Jr, Meeker $\amalg$ : Modern turtle origins: the oldest cryptodire. Science 1987, 237:289-291.

30. Gaffney ES, Meylan PA, Wyss A: A computer assisted analysis of the relationships of the higher categories of turtles. Cladistics 1991, 7:313-335.

31. Gaffney ES, Jenkins FA Jr: The cranial morphology of Kayentachelys, an Early Jurassic cryptodire, and the early history of turtles. Acta Zool 2010, 91:335-368.

32. Barley AJ, Spinks PQ, Thomson RC, Shaffer HB: Fourteen nuclear genes provide phylogenetic resolution for difficult nodes in the turtle tree of life. Mol Phylogenet Evol 2010, 55:1189-1194.

33. Guillon J-M, Guéry L, Hulin V, Girondot M: A large phylogeny of turtles (Testudines) using molecular data. Contrib Zool 2012, 81:147-158.

34. Crawford NG, Faircloth BC, McCormack JE, Brumfield RT, Winker K, Glenn TC: More than 1000 ultraconserved elements provide evidence that turtles are the sister group of archosaurs. Biol Lett 2012, 8:783-786.

35. Rambaut A: Se-Al: Sequence Alignment Editor, 2.0a11. 1996. http://evolve.zoo. ox.ac.uk.

36. Yang Z: PAML 4: phylogenetic analysis by maximum likelihood. $\mathrm{Mol}$ Biol Evol 2007, 24:1586-1591.

37. Meredith RW, Janečka JE, Gatesy J, Ryder OA, Fisher CA, Teeling EC, Goodbla A, Eizirik E, Simão TLL, Stadler T, Rabosky DL, Honeycutt RL, Flynn $\mathrm{J}$, Ingram CM, Steiner S, Williams TL, Robinson T, Burk-Herrick A, Westerman M, Ayoub NA, Springer MS, Murphy WJ: Impacts of the Cretaceous Terrestrial Revolution and $\mathrm{KPg}$ extinction on mammalian diversification. Science 2011, 334:521-524.

38. Springer MS, Meredith RW, Gatesy J, Emerling CA, Park J, Rabosky DL, Stadler T, Steiner C, Ryder OA, Janečka JE, Fisher CA, Murphy WJ: Macroevolutionary dynamics and historical biogeography of primate diversification inferred from a supermatrix. PLOS ONE 2012, 7:e45921.

39. Shedlock AM, Edwards SC: Amniotes (Amniota). In The Timetree of Life. Edited by Hedges SB, Kumar S. Oxford: Oxford Univ Press; 2009:375-379.

40. Shaffer HB: Turtles (Testudines). In The Timetree of Life. Edited by Hedges SB, Kumar S. Oxford: Oxford Univ Press; 2009:398-401.

41. Pereira SL, Baker AJ: A mitogenomic timescale for birds detects variable phylogenetic rates of molecular evolution and refutes the standard molecular clock. Mol Biol Evol 2006, 23:1731-1740.

42. Pereira SL, Baker AJ: A molecular timescale for galliform birds accounting for uncertainty in time estimates and heterogeneity of rates of DNA substitutions across lineages and sites. Mol Phylogenet Evol 2006 38:499-509.

43. van Tuinen M: Advanced birds (Neoaves). In The Timetree of Life. Edited by Hedges SB, Kumar S. Oxford: Oxford Univ Press; 2009:419-422.

44. Clarke JA: Morphology, phylogenetic taxonomy, and systematics of Ichthyornis and Apatornis (Avialae: Ornithurae). Am Mus Novitat 2006 286:1-179.
45. Delsuc F, Douzery EJP: Armadillos, anteaters, and sloths (Xenarthra). In The Timetree of Life. Edited by Hedges SB, Kumar S. Oxford: Oxford Univ Press; 2009:475-478

46. Ji Q, Luo Z-X, Yuan C-X, Wible JR, Zhang J-P, Georgi JA: The earliest known eutherian mammal. Nature 2002, 416:816-822.

47. Sasaki T, Takahashi K, Nikaido M, Miura S, Yasukawa Y, Okada N: First application of the SINE (short interspersed repetitive element) method to infer phylogenetic relationships in reptiles: an example from the turtle superfamily Testudinoidea. Mol Biol Evol 2004, 21:705-715.

48. Sire J-Y, Davit-Béal T, Delgado S, Gu X: The origin and evolution of enamel mineralization genes. Cells Tissue Organs 2007, 186:25-48.

49. Turtle Taxonomy Working Group: An annotated list of modern turtle terminal taxa with comments on areas of taxonomic instability and recent change. Chelonian Res Monogr 2007, 4:173-199.

50. Sterli J, Joyce WG: The cranial anatomy of the lower Jurassic turtle Kayentachelys apix. Acta Palaentol Polon 2007, 52:675-694.

51. Sterli J: A new, nearly complete stem turtle from the Jurassic of South America with implications for turtle evolution. Biol Lett 2008, 4:286-289.

52. Kawasaki K: The SCPP gene repertoire in bony vertebrates and graded differences in mineralized tissues. Dev Gene Evol 2009, 219:147-157.

53. Tokita M, Chaeychrmsri W, Siruntawineti J: Developmental basis of toothlessness in turtles: insight into convergent evolution of vertebrate morphology. Evolution 2012, doi:10.1111/j.1558-5646.2012.01752.x.

54. Hackett SJ, Kimball RT, Reddy S, Bowie RCK, Braun EL, Braun MJ, Chojnowski JL, Cox WA, Han K-L, Harshman J, Huddleston CJ, Marks BD, Miglia KJ, Moore WS, Sheldon FH, Steadman DW, Witt CC, Yuri T: A phylogenomic study of birds reveals their evolutionary history. Science 2008, 320:1763-1768.

55. Nakamura Y, Slaby I, Spahr A, Pezeshki G, Matsumoto K, Lyngstadaas SP: Ameloblastin fusion protein enhances pulpal healing and dentin formation in porcine teeth. Calcif Tissue Int 2006, 2006(78):278-284.

56. Tamburstuen MV, Reseland JE, Spahr A, Brookes SJ, Kvalheim G, Slaby I, Snead ML, Lyngstadaas SP: Ameloblastin expression and putative autoregulation in mesenchymal cells suggest a role in early bone formation and repair. Bone 2011, 48:406-413.

57. Turner P: Some observations on the dentition of the narwhal (Monodon monoceros). J Anat Physiol 1872, 7(Pt 1):75-79.

58. Ishiyama M: Enamel structure in odontocete whales. Scanning Microsc 1987, 1:1071-1079.

59. Nweeia MT, Eichmiller FC, Hauschka PV, Tyler E, Mead JG, Potter CW Angnatsiak DP, Richard PR, Orr JR, Black SR: Vestigial tooth anatomy and tusk nomenclature for Monodon monoceros. Anat Rec 2012, 295:1006-1016.

60. Zeichner-David M, Chen L-S, Hsu Z, Reyna J, Catón J, Bringas P: Amelogenin and ameloblastin show growth-factor like activity in periodontal ligament cells. Eur J Oral Sci 2006, 114(Suppl 1):244-253.

61. Vymětal J, Slabý I, Spahr A, Vondrášek J, Lyngstadaas SP: Bioinformatic analysis and molecular modeling of human ameloblastin suggest a twodomain intrinsically unstructured calcium-binding protein. Eur J Oral Sci 2008, 116:124-134.

62. Deutsch D, Haze-Filderman A, Blumenfeld A, Dafni L, Leiser Y, Shay B, Gruenbaum-Cohen Y, Rosenfeld E, Fermon E, Zimmermann B, Haegewald S, Bernimoulin J-P, Taylor AL: Amelogenin, a major structural protein in mineralizing enamel, is also expressed in soft tissues: brain and cells of the hematopoietic system. Eur J Oral Sci 2006, 114(Suppl 1):183-189.

63. Haze A, Taylor AL, Blumenfeld A, Rosenfeld E, Leiser Y, Dafni L, Shay B, Gruenbaum-Cohen Y, Fermon E, Haegewald S, Bernimoulin J-P, Deutsch D: Amelogenin expression in long bone and cartilage cells and in bone marrow progenitor cells. Anat Rec 2007, 290:455-460.

64. Delgado S, Ishiyama Y, Sire J-Y: Validation of amelogenesis imperfecta inferred from amelogenin evolution. J Dent Res 2007, 86:326-330.

65. Al-Hashimi N, Sire J-Y, Delgado S: Evolutionary analysis of mammalian enamelin, the largest enamel protein, supports a crucial role for the 32 $\mathrm{kDa}$ peptide and reveals selective adaptation in rodents and primates. J Mol Evol 2009, 69:635-656.

doi:10.1186/1471-2148-13-20

Cite this article as: Meredith et al:: Molecular decay of enamel matrix protein genes in turtles and other edentulous amniotes. $B M C$ Evolutionary Biology 2013 13:20 